\title{
COVID-19 outbreak in a long-term care facility in Kelowna, British Columbia after rollout of COVID-19 vaccine in March 2021
}

\author{
Fatemeh Sabet ${ }^{1,2}$, Barbara Gauthier ${ }^{3}$, Muddassir Siddiqui ${ }^{3}$, Amanda Wilmer ${ }^{4}$, Natalie Prystajecky ${ }^{4,5}$, \\ Pamela Rydings ${ }^{3}$, Michele Andrews ${ }^{3}$, Sue Pollock ${ }^{3,6 *}$
}

\begin{abstract}
Background: In March 2021, a coronavirus disease 2019 (COVID-19) outbreak was declared at a large long-term care and short stay facility in British Columbia, Canada-well after introduction of the vaccination program in long-term care facilities that resulted in a dramatic decline in the number of outbreaks in this type of setting. The objective of this study is to provide the descriptive epidemiology of this outbreak, in the context of partial immunization of both residents and staff at the facility.
\end{abstract}

Methods: The cases' information was extracted from a provincial information system (Panorama). Descriptive analysis was performed using Microsoft Excel and SAS. Outbreak management controls included, but were not limited to, asymptomatic testing and efforts to increase vaccination.

Results: Twenty-six cases among the 241 resident and three cases among the 418 staff (corresponding to attack rates of $10 \%$ and less than $1 \%$, respectively) were identified. The attack rate in residents was considerably lower than the average attack rate for COVID-19 outbreaks in long-term care facilities before the vaccine rollout. Seventeen resident cases were either partially or fully immunized. Four of the eight hospitalized cases and two of the three deceased cases were partially immunized. Seventeen cases were temporary stay residents. The three staff cases were not vaccinated. Ten cases were identified as part of asymptomatic testing.

Conclusion: Introduction of vaccination at facilities contributed to lower attack rates and higher numbers of asymptomatic cases in this outbreak. Screening asymptomatic individuals identified additional cases among vaccinated residents. Findings underscore the importance of achieving high vaccine coverage, including among temporary stay residents, to prevent virus introduction and subsequent unrecognized transmission opportunities.
This work is licensed under a Creative Commons Attribution 4.0 International License.

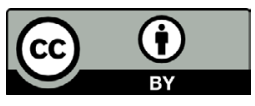

Affiliations

${ }^{1}$ Public Health and Preventive Medicine Residency Program, University of Calgary, Calgary, AB

${ }^{2}$ Alberta Health Services, Calgary, $\mathrm{AB}$

${ }^{3}$ Population Health, Interior Health Authority Kelowna, BC

${ }^{4}$ Pathology and Laboratory Medicine, University of British Columbia, Vancouver, BC

${ }^{5}$ British Columbia Centre for Disease Control Public Health Laboratory, Vancouver, BC

${ }^{6}$ School of Population and Public Health, University of British Columbia, Vancouver, BC

\section{*Correspondence: \\ sue.pollock@interiorhealth.ca}

Suggested citation: Sabet FA, Gauthier B, Siddiqui M, Wilmer A, Prystajecky N, Rydings P, Andrews M, Pollock SL. COVID-19 outbreak in a long-term care facility in Kelowna, British Columbia after rollout of COVID-19 vaccine in March 2021. Can Commun Dis Rep 2021;47(12):543-52. https://doi.org/10.14745/ccdr.v47i12a05

Keywords: long-term care, outbreak, COVID-19 vaccine, descriptive epidemiology

\section{Introduction}

The coronavirus disease 2019 (COVID-19) pandemic, declared in March 2020, has physically and mentally affected many lives, especially seniors and individuals living with underlying medical conditions. Long-term care (LTC) facilities experienced an increase in outbreaks, as well as increased morbidity and mortality amongst staff and residents $(1,2)$.
Vaccination of frontline staff has been found to be highly effective in preventing COVID-19 infection (3); however, older adults with multiple underlying comorbidities were one of the groups not included in the preauthorization vaccine effectiveness clinical trials and are expected to have lower immunogenicity from vaccination (4). Other studies in this population have focused on vaccine effectiveness in the post-marketing phase in individuals with partial versus complete immunization $(3,5)$. A 
recent publication on vaccine effectiveness among residents of nursing homes in the United States showed a reduction in the number of infections and milder symptoms among individuals who were partially or fully vaccinated (6). In addition, the emergence of new variants of severe acute respiratory syndrome coronavirus 2 (SARS-CoV-2) has raised questions about vaccine effectiveness against novel strains of the virus (7-9).

In March 2021, Interior Health $(\mathrm{IH}$; a regional health authority in British Columbia, Canada) reported the end of the third wave of the pandemic. Although the incidence rate of COVID-19 infection in $\mathrm{IH}$ was decreasing at that time, the prevalence of variants of concern was starting to increase, particularly the Alpha (B.1.1.7) variant. Providing the COVID-19 vaccine to seniors in LTC facilities in British Columbia resulted in a significant decrease in the number of COVID-19 outbreaks and deaths at these facilities (10). However, a COVID-19 outbreak occurred at a large LTC facility three months after the start of vaccination program. On March 5, 2021, IH Communicable Disease Unit and Infection Prevention and Control (IPAC) were notified of a positive COVID-19 result in a resident of a LTC facility who had been admitted in December 2020 to the short stay unit (SSU) from a nearby acute care site for rehabilitation. The resident, who had hypothyroidism and hypertension as their underlying medical condition and who had received their second dose of the Pfizer-BioNTech COVID-19 vaccine eight days prior to symptom onset, was isolated in a private room with mild symptoms, including sore throat, cough, congestion and fatigue.

The same day, it was discovered that another resident, who was unknowingly exposed to a COVID-19-positive roommate in an acute care setting outbreak, had recently been transferred back to a different unit in the same LTC facility. This resident underwent testing on March 6, 2021, and was found to be COVID-19 positive. This resident had been admitted to the acute care site for renal failure and sepsis secondary to urinary tract infection and the only COVID-19 infection symptom was fatigue. The acute care setting outbreak included five staff and five patients and was declared over on April 7, 2021.

The LTC facility was unique in that it comprised 181 beds divided between four LTC units and included a 60-bed SSU as well. Resident rooms were a mix of private, semi-private and multi-bedrooms. There were approximately 418 staff working at the facility during the outbreak: approximately 70 SSU staff and 208 LTC staff, plus 140 staff working in both areas of the facility.

The IPAC measures at the facility before the outbreak began included the restrictions that were in place for LTC facilities in British Columbia as per the provincial guidelines (11). These measures included but were not limited to daily screening of staff and residents, use of appropriate personal protective equipment, regular hand hygiene and frequent environmental cleaning. Social visits were restricted to one designated visitor, subject to strict symptom screening, at two meters of distance with personal protective equipment in place. Staff were restricted to work at a single LTC site. The facility was required to perform daily reports of any symptomatic residents or staff.

\section{Outbreak control measures}

A subgroup of the Communicable Disease Unit called the Adult Care Facility COVID-19 Response Team was created as a pandemic response to oversee COVID-19 outbreaks related to LTC facilities in early 2020. The Adult Care Facility Team assembled an outbreak management team including the local Medical Health Officer, IPAC, Environmental Public Health, Epidemiology, Community Care Licensing, Clinical Operations, Workplace Health and Safety, Emergency Response Team, Communications and representatives of the facility. Introduction of outbreak management measures started within a day of the identification of the index case.

After the initial outbreak management team assessment, an outbreak was declared and ongoing daily meetings occurred. Residents were isolated to their private rooms or beds from the start of the outbreak until a cohorting plan was developed. Ongoing screening occurred daily to identify newly symptomatic staff or residents who were then placed in isolation, tested for COVID-19 and reported as soon as possible. New positive cases were added to an outbreak line list. Symptomatic staff were excluded from work. Staff were cohorted and started to work exclusively at designated units within the facility. Contact tracing was performed as positive cases were identified, with exposed individuals cohorted and pre-emptively placed in isolation.

The IPAC support provided education and direction on infection control practices. Resident activities were cancelled and meals were served only at resident rooms. Unimmunized residents and staff were immediately offered the vaccine. Vaccination of the recently infected residents and staff was delayed due to natural immunity following infection. Asymptomatic testing was performed to detect cases and prevent unrecognized facility transmission.

The objective of this report is to provide descriptive epidemiology for a COVID-19 outbreak in a large LTC facility, which was more open to movement of residents and staff owing to the unique co-location of an SSU, in the context of partial immunization of both residents and staff.

\section{Methods}

\section{Case finding and data collection}

The IPAC and Communicable Disease Unit staff began an investigation of residents and staff, under the direction of the Medical Health Officer. Facility-related cases were defined as per provincial outbreak guidelines (12). Cases were defined as individuals with a positive COVID-19 polymerase chain reaction test result, regardless of symptoms and standardized information was collected on any confirmed cases (13). Investigation was completed for any additional case starting February 18, 2021- 
one incubation period prior to the first identified case-for likely linkage to the outbreak.

Specimen collection and testing were undertaken following provincial guidelines. Flocked nasopharyngeal swabs (residents) or saline gargles (staff) were collected, then were rapidly transported to Kelowna General Hospital laboratory for testing on the Panther Fusion ${ }^{\circledR}$ SARS-CoV-2 Assay (Hologic, San Diego, California, United States) or the Allplex ${ }^{\mathrm{TM}} 2019-$ nCOV Assay $^{2}$ (Seegene, Seoul, South Korea). Positive specimens were referred to British Columbia Centre for Disease Control Public Health Laboratory for whole genome sequencing.

Information about reportable cases, including their immunization records, was available through Panorama, the British Columbia Public Health Communicable Disease Unit's integrated records system (13). Staff immunization records were extracted from Panorama using Public Health Environment for Integrated data Extracts (PHENIX). Immunization records for residents that were not cases were provided by Interior Health's Strategic Information team. Descriptive analyses were performed using Microsoft Excel 2010 and SAS version 9.4.

Unvaccinated cases are defined as individuals who either had not received a vaccine or had received only one dose of vaccine within 21 days of episode date (symptom onset when available, otherwise specimen collection date for first positive test). Partially vaccinated individuals had received the first dose of vaccine more than 21 days before their episode date and either had not received the second dose of vaccine or had received the second dose within seven days of their onset of symptoms. Individuals with episode dates more than seven days after receiving their second dose of vaccine are considered fully vaccinated. This definition was adapted provincially for partial and full vaccination at the time that the outbreak happened (14).

Asymptomatic COVID-19 polymerase chain reaction testing was performed in a ring screen model, with the highest-risk asymptomatic resident and staff contacts tested first, and with subsequent testing in more remote contacts as additional cases were identified. Asymptomatic testing was performed at five to seven-day intervals, in multiple rounds based on the level of COVID-19 activity in the staff and residents on a particular unit.

\section{Results}

A resident of SSU was identified as the first case with disease onset on February 25, 2021. Over the next two weeks, the disease was spread to staff and two other units in the facility. The outbreak was declared over on May 5, 2021 (Figure 1).

\section{Figure 1: Epidemic curve of outbreak cases by episode} date $^{\mathrm{a}, \mathrm{b}}$, unit and role (resident/staff) $(\mathrm{N}=29)$

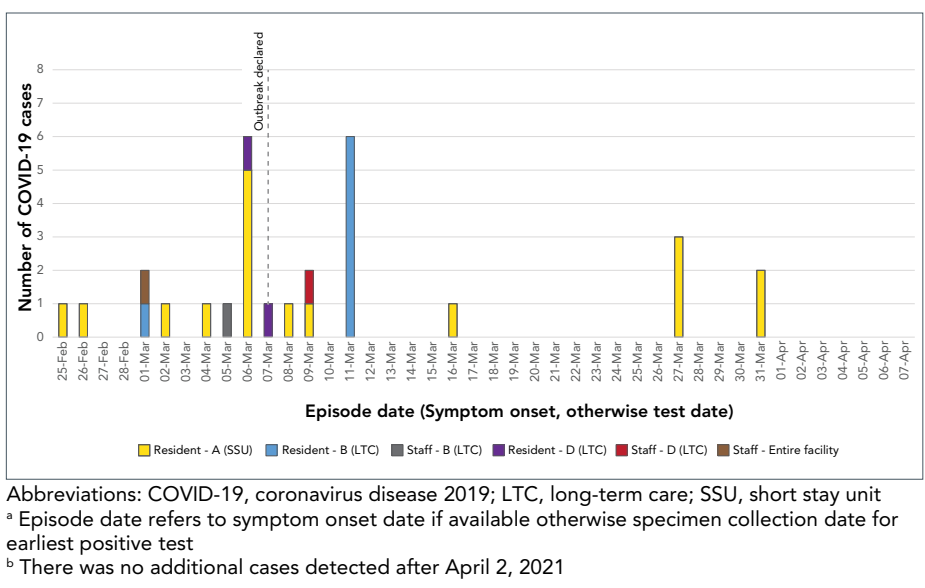

When the outbreak was declared, resident immunization rates were similar for the LTC units and the SSU for COVID-19 vaccine dose one $(91.1 \%$ vs $87.7 \%$, respectively) but were different for vaccine dose two $(82.8 \%$ of LTC residents and $22.8 \%$ of SSU residents had received their second dose). Staff full vaccination rate decreased slightly from $58 \%$ to $54 \%$ during the course of the outbreak; however, partial vaccination rate increased from $6 \%$ to $19 \%$ from the date that the outbreak was declared until it was declared over.

Ten of 29 cases were asymptomatic: all were resident cases and were identified as part of the asymptomatic testing conducted in response to the outbreak (Table 1 ). Six of the ten asymptomatic cases were fully vaccinated. Eight of the 26 resident cases were hospitalized and there were three COVID-19-related deaths. All deaths occurred among cases that were at least partially vaccinated and four of the eight hospitalizations were also among partially vaccinated cases (Table 2 ).

Table 1: Characteristics of COVID-19 cases included in the outbreak investigation by role (resident/staff) $(\mathrm{N}=29)$

\begin{tabular}{|c|c|c|c|c|c|c|}
\hline \multirow{2}{*}{ Characteristics of the cases } & \multicolumn{2}{|c|}{ Residents } & \multicolumn{2}{|c|}{ Staff } & \multicolumn{2}{|c|}{ Total } \\
\hline & Number & $\%$ & Number & $\%$ & Number & $\%$ \\
\hline Total cases & 26 & $100.0 \%$ & 3 & $100.0 \%$ & 29 & $100.0 \%$ \\
\hline \multicolumn{7}{|l|}{ Sex } \\
\hline Males & 4 & $15.4 \%$ & 1 & $33.3 \%$ & 3 & $10.3 \%$ \\
\hline Females & 16 & $61.5 \%$ & 2 & $66.7 \%$ & 10 & $34.5 \%$ \\
\hline \multicolumn{7}{|l|}{ Age group } \\
\hline Younger than 30 years & 0 & $0.0 \%$ & 0 & $0.0 \%$ & 0 & $0.0 \%$ \\
\hline 30-39 years & 0 & $0.0 \%$ & 1 & $33.3 \%$ & 1 & $3.4 \%$ \\
\hline
\end{tabular}


Table 1: Characteristics of COVID-19 cases included in the outbreak investigation by role (resident/staff) $(\mathrm{N}=29)$ (continued)

\begin{tabular}{|c|c|c|c|c|c|c|}
\hline \multirow{2}{*}{ Characteristics of the cases } & \multicolumn{2}{|c|}{ Residents } & \multicolumn{2}{|c|}{ Staff } & \multicolumn{2}{|c|}{ Total } \\
\hline & Number & $\%$ & Number & $\%$ & Number & $\%$ \\
\hline 40-49 years & 1 & $3.8 \%$ & 0 & $0.0 \%$ & 1 & $3.4 \%$ \\
\hline $50-59$ years & 0 & $0.0 \%$ & 2 & $66.7 \%$ & 2 & $6.9 \%$ \\
\hline $60-69$ years & 0 & $0.0 \%$ & 0 & $0.0 \%$ & 0 & $0.0 \%$ \\
\hline 70-79 years & 5 & $19.2 \%$ & 0 & $0.0 \%$ & 5 & $17.2 \%$ \\
\hline $80-89$ years & 11 & $42.3 \%$ & 0 & $0.0 \%$ & 11 & $37.9 \%$ \\
\hline $90+$ years & 9 & $34.6 \%$ & 0 & $0.0 \%$ & 9 & $31.0 \%$ \\
\hline \multicolumn{7}{|l|}{ Unit } \\
\hline $\mathrm{A}(\mathrm{SSU})$ & 17 & $65.4 \%$ & 0 & $0.0 \%$ & 17 & $58.6 \%$ \\
\hline B (LTC) & 7 & $26.9 \%$ & 1 & $33.3 \%$ & 8 & $27.6 \%$ \\
\hline $\mathrm{D}(\mathrm{LTC})$ & 2 & $7.7 \%$ & 1 & $33.3 \%$ & 3 & $10.3 \%$ \\
\hline Entire facility & 0 & $0.0 \%$ & 1 & $33.3 \%$ & 0 & $0.0 \%$ \\
\hline \multicolumn{7}{|l|}{ Vaccination status } \\
\hline Unvaccinated & 9 & $34.6 \%$ & 3 & $100.0 \%$ & 11 & $37.9 \%$ \\
\hline Partially vaccinated & 9 & $34.6 \%$ & 0 & $0.0 \%$ & 10 & $34.5 \%$ \\
\hline Fully vaccinated & 8 & $30.8 \%$ & 0 & $0.0 \%$ & 8 & $27.6 \%$ \\
\hline \multicolumn{7}{|l|}{ Chronic medical conditions ${ }^{a}$} \\
\hline Any (total) & 17 & $65.4 \%$ & 0 & $0.0 \%$ & 17 & $58.6 \%$ \\
\hline Cardiac disease & 13 & $50.0 \%$ & 0 & $0.0 \%$ & 14 & $48.3 \%$ \\
\hline Pulmonary disease & 5 & $19.2 \%$ & 0 & $0.0 \%$ & 7 & $24.1 \%$ \\
\hline Kidney disease & 2 & $7.7 \%$ & 0 & $0.0 \%$ & 5 & $17.2 \%$ \\
\hline Other & 6 & $23.1 \%$ & 0 & $0.0 \%$ & 10 & $34.5 \%$ \\
\hline None & 9 & $34.6 \%$ & 3 & $100.0 \%$ & 12 & $41.4 \%$ \\
\hline \multicolumn{7}{|l|}{ Disease status } \\
\hline Asymptomatic & 10 & $38.5 \%$ & 0 & $0.0 \%$ & 10 & $34.5 \%$ \\
\hline Symptomatic & 5 & $19.2 \%$ & 3 & $100.0 \%$ & 8 & $27.6 \%$ \\
\hline Hospitalized & 8 & $30.8 \%$ & 0 & $0.0 \%$ & 8 & $27.6 \%$ \\
\hline ICU & 0 & $0.0 \%$ & 0 & $0.0 \%$ & 0 & $0.0 \%$ \\
\hline Death & 3 & $11.5 \%$ & 0 & $0.0 \%$ & 3 & $10.3 \%$ \\
\hline \multicolumn{7}{|l|}{ SARS-CoV-2 lineage } \\
\hline B.1.160 & 16 & $61.5 \%$ & 2 & $66.7 \%$ & 18 & $62.1 \%$ \\
\hline B.1.36 & 1 & $3.8 \%$ & 0 & $0.0 \%$ & 1 & $3.4 \%$ \\
\hline Insufficient nucleic acid for WGS & 9 & $34.6 \%$ & 1 & $33.3 \%$ & 10 & $34.5 \%$ \\
\hline \multicolumn{7}{|l|}{ Ct value } \\
\hline Less than 30.0 & 17 & $65.4 \%$ & 2 & $66.7 \%$ & 19 & $65.5 \%$ \\
\hline 30.0 or higher & 9 & $34.6 \%$ & 1 & $33.3 \%$ & 10 & $34.5 \%$ \\
\hline
\end{tabular}

Abbreviations: COVID-19, coronavirus disease 2019; Ct value, cycle threshold value; ICU, intensive care unit; LTC, long-term care; SARS-CoV-2, severe acute respiratory syndrome coronavirus 2 ;

SSU, short stay unit; WGS, whole genome sequencing

${ }^{a}$ Breakdown of type chronic medical conditions may add to more than $100 \%$ as it was possible for cases to have more than one condition 
Table 2: Characteristics of COVID-19 cases included in the outbreak investigation by vaccination status $(\mathrm{N}=29)$

\begin{tabular}{|c|c|c|c|c|c|c|}
\hline \multirow{2}{*}{ Characteristics of the cases } & \multicolumn{2}{|c|}{ Unimmunized } & \multicolumn{2}{|c|}{ Partially vaccinated } & \multicolumn{2}{|c|}{ Fully vaccinated } \\
\hline & Number & $\%$ & Number & $\%$ & Number & $\%$ \\
\hline Total cases & 12 & $100.0 \%$ & 9 & $100.0 \%$ & 8 & $100.0 \%$ \\
\hline \multicolumn{7}{|l|}{ Sex } \\
\hline Males & 3 & $25.0 \%$ & 2 & $20.2 \%$ & 1 & $12.5 \%$ \\
\hline Females & 9 & $75.0 \%$ & 8 & $88.9 \%$ & 7 & $87.5 \%$ \\
\hline \multicolumn{7}{|l|}{ Age group } \\
\hline Younger than 30 years & 0 & $0.0 \%$ & 0 & $0.0 \%$ & 0 & $0.0 \%$ \\
\hline $30-39$ years & 1 & $8.3 \%$ & 0 & $0.0 \%$ & 0 & $0.0 \%$ \\
\hline $40-49$ years & 1 & $8.3 \%$ & 0 & $0.0 \%$ & 0 & $0.0 \%$ \\
\hline $50-59$ years & 2 & $16.7 \%$ & 0 & $0.0 \%$ & 0 & $0.0 \%$ \\
\hline $60-69$ years & 0 & $0.0 \%$ & 0 & $0.0 \%$ & 0 & $0.0 \%$ \\
\hline 70-79 years & 2 & $16.7 \%$ & 1 & $11.1 \%$ & 2 & $25.0 \%$ \\
\hline $80-89$ years & 5 & $41.7 \%$ & 3 & $33.3 \%$ & 3 & $37.5 \%$ \\
\hline $90+$ years & 1 & $8.3 \%$ & 5 & $55.6 \%$ & 3 & $37.5 \%$ \\
\hline \multicolumn{7}{|l|}{ Role } \\
\hline Resident & 9 & $75.0 \%$ & 9 & $100.0 \%$ & 8 & $100.0 \%$ \\
\hline Staff & 3 & $25.0 \%$ & 0 & $0.0 \%$ & 0 & $0.0 \%$ \\
\hline \multicolumn{7}{|l|}{ Unit } \\
\hline$A(S S U)$ & 8 & $66.7 \%$ & 7 & $77.8 \%$ & 2 & $25.0 \%$ \\
\hline B (LTC) & 1 & $8.3 \%$ & 1 & $11.1 \%$ & 6 & $75.0 \%$ \\
\hline $\mathrm{D}(\mathrm{LTC})$ & 2 & $16.7 \%$ & 1 & $11.1 \%$ & 0 & $0.0 \%$ \\
\hline Entire facility & 1 & $8.3 \%$ & 0 & $0.0 \%$ & 0 & $0.0 \%$ \\
\hline \multicolumn{7}{|l|}{ Chronic medical conditions ${ }^{\mathrm{a}}$} \\
\hline Any (total) & 5 & $41.7 \%$ & 7 & $77.8 \%$ & 5 & $62.5 \%$ \\
\hline Cardiac disease & 3 & $25.0 \%$ & 5 & $55.6 \%$ & 5 & $62.5 \%$ \\
\hline Pulmonary disease & 2 & $16.7 \%$ & 2 & $22.2 \%$ & 1 & $12.5 \%$ \\
\hline Kidney disease & 1 & $8.3 \%$ & 0 & $0.0 \%$ & 1 & $12.5 \%$ \\
\hline Other & 4 & $33.3 \%$ & 1 & $11.1 \%$ & 1 & $12.5 \%$ \\
\hline None & 7 & $58.3 \%$ & 2 & $22.2 \%$ & 3 & $37.5 \%$ \\
\hline \multicolumn{7}{|l|}{ Disease status } \\
\hline Asymptomatic & 4 & $33.3 \%$ & 0 & $0.0 \%$ & 6 & $75.0 \%$ \\
\hline Symptomatic & 4 & $33.3 \%$ & 3 & $33.3 \%$ & 1 & $12.5 \%$ \\
\hline Hospitalized & 4 & $33.3 \%$ & 4 & $44.4 \%$ & 0 & $0.0 \%$ \\
\hline ICU & 0 & $0.0 \%$ & 0 & $0.0 \%$ & 0 & $0.0 \%$ \\
\hline Death & 0 & $0.0 \%$ & 2 & $22.2 \%$ & 1 & $12.5 \%$ \\
\hline \multicolumn{7}{|l|}{ SARS-CoV-2 lineage } \\
\hline B.1.160 & 8 & $66.7 \%$ & 6 & $66.7 \%$ & 4 & $50.0 \%$ \\
\hline B.1.36 & 1 & $8.3 \%$ & 0 & $0.0 \%$ & 0 & $0.0 \%$ \\
\hline Insufficient nucleic acid for WGS & 3 & $25.0 \%$ & 3 & $33.3 \%$ & 4 & $50.0 \%$ \\
\hline \multicolumn{7}{|l|}{ Ct value } \\
\hline Less than 30.0 & 10 & $83.3 \%$ & 6 & $66.7 \%$ & 3 & $37.5 \%$ \\
\hline 30.0 or higher & 2 & $16.7 \%$ & 3 & $33.3 \%$ & 5 & $62.5 \%$ \\
\hline
\end{tabular}

Abbreviations: COVID-19, coronavirus disease 2019; Ct value, cycle threshold value; ICU, intensive care unit; LTC, long-term care; SARS-CoV-2, severe acute respiratory syndrome coronavirus 2 ;

SSU, short stay unit; WGS, whole genome sequencing

a Breakdown of type chronic medical conditions may add to more than $100 \%$ as it was possible for cases to have more than one condition 
Of the 26 resident cases, 17 were fully or partially vaccinated (Table 1). All three staff cases within this outbreak were unvaccinated. The majority of cases that were considered fully vaccinated break through cases was from Unit B, where residents had higher opportunity to get their second dose of vaccine compared with other units. The majority of cases that were considered unvaccinated was from the SSU (Table 2).

Despite its smaller bed capacity compared with the other facility units, 17 of the 26 cases were from the SSU where the index case occurred. The attack rate at SSU was $28 \%$. A higher proportion of resident cases were females with ages above 80 years that reflected the demographic profile in the facility. Seventeen of 26 resident cases (65\%) had some underlying chronic medical condition, and this proportion was higher among residents from the LTC unit (Table 3). The disease outcomes were more prominent amongst the resident of SSU as there were higher proportion of severe outcomes that occurred in this unit compared with the other two units.
All the samples from resident cases that were successfully sequenced at SSU and Unit B were identified as the SARS-CoV-2 lineage B.1.160 $(n=13)$. All thirteen B.1.160 cases cluster together within three mutations. However, one resident case at Unit D was successfully sequenced and was genetically different, identified as B.1.136 lineage (Figure 2). Ten cases had cycle threshold $(\mathrm{Ct})$ values over 30.0, nine of whom were asymptomatic cases. Eight of ten cases with higher $\mathrm{Ct}$ values were among those considered at least partially vaccinated (Table 1 and Table 2).

The average attack rate at the facility was $10 \%$ in residents and less than $1 \%$ in staff. The resident attack rate in the short stay unit of the facility was $22 \%$ compared with $4 \%$ in the LTC units.

Clinical Operations was able to arrange on site vaccination for residents. Staff were provided with educational material about vaccination and were strongly encouraged to access vaccine through local public health facilities. The proportion of resident vaccination rate did not change significantly during the course of the outbreak. Staff immunization with at least one dose of vaccine increased from $63.8 \%$ to $72.5 \%$.

Table 3: Characteristics of COVID-19 resident cases included in the outbreak investigation by unit $(\mathrm{N}=26)$

\begin{tabular}{|c|c|c|c|c|c|c|}
\hline \multirow{2}{*}{ Characteristics of the cases } & \multicolumn{2}{|c|}{ Unit A (SSU) } & \multicolumn{2}{|c|}{ Unit B (LTC) } & \multicolumn{2}{|c|}{ Unit D (LTC) } \\
\hline & Number & $\%$ & Number & $\%$ & Number & $\%$ \\
\hline Total resident cases & 17 & $100.0 \%$ & 7 & $100.0 \%$ & 2 & $100.0 \%$ \\
\hline \multicolumn{7}{|l|}{ Sex } \\
\hline Males & 2 & $11.8 \%$ & 1 & $14.3 \%$ & 0 & $0.0 \%$ \\
\hline Females & 15 & $88.2 \%$ & 6 & $85.7 \%$ & 2 & $100.0 \%$ \\
\hline \multicolumn{7}{|l|}{ Age group } \\
\hline Younger than 70 years & 0 & $0.0 \%$ & 0 & $0.0 \%$ & 1 & $50.0 \%$ \\
\hline $70-79$ years & 4 & $23.5 \%$ & 1 & $14.3 \%$ & 0 & $0.0 \%$ \\
\hline $80-89$ years & 9 & $52.9 \%$ & 2 & $28.6 \%$ & 0 & $0.0 \%$ \\
\hline $90+$ years & 4 & $23.5 \%$ & 4 & $57.1 \%$ & 1 & $50.0 \%$ \\
\hline \multicolumn{7}{|l|}{ Vaccination status } \\
\hline Unvaccinated & 8 & $47.1 \%$ & 0 & $0.0 \%$ & 1 & $50.0 \%$ \\
\hline Partially vaccinated & 7 & $41.2 \%$ & 1 & $14.3 \%$ & 1 & $50.0 \%$ \\
\hline Fully vaccinated & 2 & $11.8 \%$ & 6 & $85.7 \%$ & 0 & $0.0 \%$ \\
\hline \multicolumn{7}{|l|}{ Chronic medical conditions ${ }^{\mathrm{a}}$} \\
\hline Any (total) & 10 & $58.8 \%$ & 5 & $71.4 \%$ & 2 & $100.0 \%$ \\
\hline Cardiac disease & 7 & $41.2 \%$ & 5 & $71.4 \%$ & 1 & $50.0 \%$ \\
\hline Pulmonary disease & 4 & $23.5 \%$ & 1 & $14.3 \%$ & 0 & $0.0 \%$ \\
\hline Kidney disease & 1 & $5.9 \%$ & 1 & $14.3 \%$ & 0 & $0.0 \%$ \\
\hline Other & 4 & $23.5 \%$ & 1 & $14.3 \%$ & 1 & $50.0 \%$ \\
\hline None & 7 & $41.2 \%$ & 2 & $28.6 \%$ & 0 & $0.0 \%$ \\
\hline \multicolumn{7}{|l|}{ Disease status } \\
\hline Asymptomatic & 4 & $23.5 \%$ & 5 & $71.4 \%$ & 1 & $50.0 \%$ \\
\hline Symptomatic & 4 & $23.5 \%$ & 0 & $0.0 \%$ & 1 & $50.0 \%$ \\
\hline Hospitalized & 7 & $41.2 \%$ & 1 & $14.3 \%$ & 0 & $0.0 \%$ \\
\hline $\mathrm{ICU}$ & 0 & $0.0 \%$ & 0 & $0.0 \%$ & 0 & $0.0 \%$ \\
\hline Death & 2 & $11.8 \%$ & 1 & $14.3 \%$ & 0 & $0.0 \%$ \\
\hline
\end{tabular}


Table 3: Characteristics of COVID-19 resident cases included in the outbreak investigation by unit $(\mathrm{N}=\mathbf{2 6})$ (continued)

\begin{tabular}{|c|c|c|c|c|c|c|}
\hline \multirow{2}{*}{ Characteristics of the cases } & \multicolumn{2}{|c|}{ Unit A (SSU) } & \multicolumn{2}{|c|}{ Unit B (LTC) } & \multicolumn{2}{|c|}{ Unit D (LTC) } \\
\hline & Number & $\%$ & Number & $\%$ & Number & $\%$ \\
\hline \multicolumn{7}{|l|}{ SARS-CoV-2 lineage } \\
\hline B.1.160 & 12 & $70.6 \%$ & 4 & $57.1 \%$ & 0 & $0.0 \%$ \\
\hline B.1.36 & 0 & $0.0 \%$ & 0 & $0.0 \%$ & 1 & $50.0 \%$ \\
\hline Insufficient nucleic acid for WGS & 5 & $29.4 \%$ & 3 & $42.9 \%$ & 1 & $50.0 \%$ \\
\hline \multicolumn{7}{|l|}{ Ct value } \\
\hline Less than 30.0 & 13 & $76.5 \%$ & 3 & $42.9 \%$ & 1 & $50.0 \%$ \\
\hline 30.0 or higher & 4 & $23.5 \%$ & 4 & $57.1 \%$ & 1 & $50.0 \%$ \\
\hline
\end{tabular}

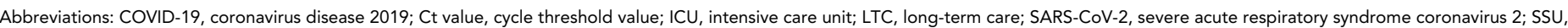
short stay unit; WGS, whole genome sequencing

a Breakdown of type chronic medical conditions may add to more than $100 \%$ as it was possible for cases to have more than one condition

Figure 2: Phylogenetic tree demonstrating severe acute respiratory syndrome coronavirus 2 genetic diversity of the cases linked to the outbreak ${ }^{a}$

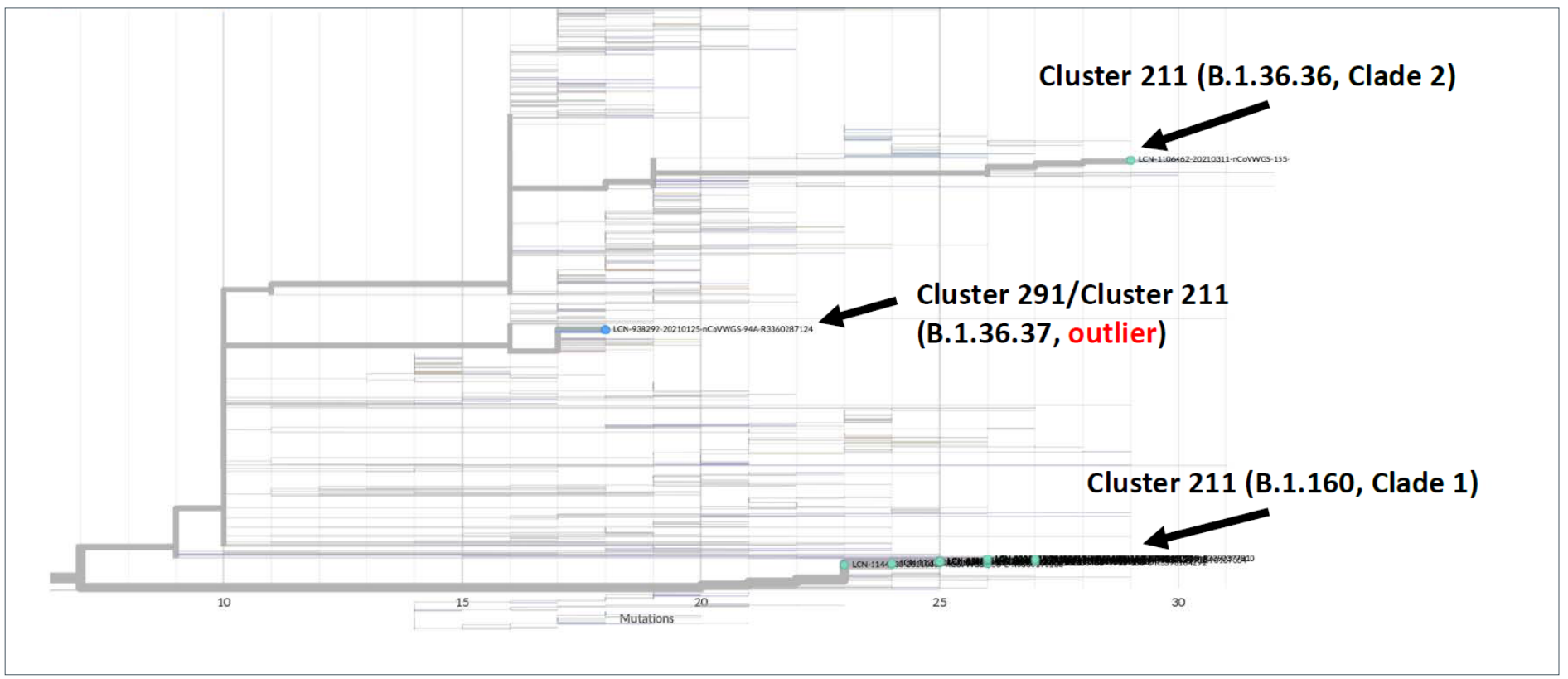

Abbreviation: SSU, short stay unit

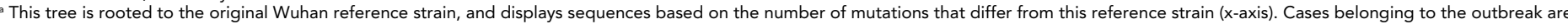
displayed as light blue and green dots on the tree tips

\section{Discussion}

An outbreak in a LTC Facility in Kelowna represented one of the few LTC outbreaks after introduction of vaccination to this population in British Columbia. The attack rate in residents at the facility was considerably lower than the average attack rate for COVID-19 outbreaks in LTC facilities before the vaccine rollout and the number of asymptomatic cases was relatively higher. To compare the numbers, the average attack rate for COVID-19 outbreaks in LTC facilities before the vaccine rollout was $45 \%$ (ranging from $5 \%$ to $90 \%$ ). The average attack rate of the facility outbreaks is calculated based on the information on declared outbreaks and total cases available on British Columbia Centre for Disease Control website (15).
In this outbreak, most of the breakthrough cases were among the partially vaccinated residents. This finding is consistent with two cohort studies that show lower antibody response to first dose of vaccination in population older than 80 years of age $(16,17)$. Six of 10 cases that were identified among the fully vaccinated residents were detected by asymptomatic testing with high $\mathrm{Ct}$ values. Similarly, another study demonstrated complete vaccination with messenger ribonucleic acid (mRNA) vaccines to be $94 \%$ effective against hospitalization for adults, while partial vaccination was $65 \%$ effective against hospitalization for adults older than 65 years of age (18).

The LTC facilities in IH had an overall low vaccination rate (68\%) at the time of this outbreak, which contributed to the ongoing transmission. Shared dietary and housekeeping staff between 
the LTC units and SSU was another factor that likely facilitated introduction of the infection to different units. Despite efforts to increase staff vaccination rate, the rate of full vaccination decreased slightly during the outbreak (from $58 \%$ to $54 \%$ ). The slight decrease was due to staff movement in and out of the facility during the course of outbreak management. Outbreak protocols were successful in increasing the partial vaccination rate among staff. In addition, the structural characteristics of the facility (a large, aging building and multi-bed rooms) likely contributed to the outbreak.

\section{Unit A (short stay unit)}

The attack rate was higher in the SSU than in the LTC units. The residents were not required to be vaccinated prior to arrival at SSU and due to the transient nature of resident's visit at this unit, complete immunization rate was lower than LTC side. High turnover at the facility and high volume of traffic through the facility due to rehabilitation services were other factors that likely facilitated transmission within the unit. Recurrent transfers between this unit and a nearby acute care setting increased the need for vigilant screening of the admissions.

The resident partial vaccination rate at this unit was high before the outbreak and did not have a meaningful change during the course of the outbreak; however, staff vaccination rate increased by $10 \%$. The strict outbreak measures and the improved vaccination rate and/or acquisition of natural immunity following infection facilitated outbreak management. However, due to the limited vaccine supply and to accelerate the initiation of vaccination in the population, a decision was made provincially to extend the interval between the first and second dose of vaccination at the beginning of March $2021(19,20)$. Therefore, full vaccination of some of the residents and staff was delayed.

All of the cases that required hospitalization at this unit were partially or fully vaccinated and had chronic medical conditions. Two deaths were reported in partially or fully vaccinated individuals with multiple underlying chronic medical conditions. Their deaths were primarily related to their underlying conditions and COVID-19 infection was a contributory factor.

\section{Unit B (long-term care)}

The cases at this unit were linked to the SSU (Figure 2). While all the confirmed cases were considered partially or fully vaccinated, these definitions rely on an assessment of status at episode date. Most of the cases diagnosed had $\mathrm{Ct}$ values in higher ranges and were asymptomatic. It is possible that the cases may have had earlier infections that were not detected until they underwent asymptomatic testing. It is also possible that since most of these cases were fully vaccinated, they had lower viral load and decreased severity of infection.

\section{Unit D (long-term care)}

The initial case at this unit was transferred to the LTC from an acute care setting. This resident then transmitted infection to one other resident on the unit. These two cases identified on this unit were unvaccinated and were transferred to the SSU early in the course of the outbreak for cohorting purposes. The viral lineage identified for these cases was the same as that from the acute care facility outbreak, demonstrating that these two cases were unrelated to the outbreak in the rest of the facility.

\section{Strengths and limitations}

This is one of the initial studies describing an outbreak in a LTC setting after the introduction of the COVID-19 vaccination. It includes a comprehensive assessment of the cases that were partially or fully vaccinated to contribute to the growing body of evidence concerning the attack rate and disease outcome in immunized individuals. In addition, whole genome sequencing and phylogenetic assessment supplemented the epidemiologic investigation to clarify the disease transmission patterns. This study demonstrates the complexity of managing an outbreak in this setting and can inform outbreak prevention and management in LTC facilities.

A number of factors limits this study. A proper assessment of vaccine effectiveness and disease outcome requires a larger sample size to compare between vaccinated and unvaccinated groups, in order to adjust for confounding factors that can contribute to severe symptoms in population with advanced age. However, the number of cases linked to this outbreak was small and the cases were heterogeneous and belonged to different cohorts with distinct lineages of virus, limiting the power of statistical analysis. In addition, due to the specific characteristics of the outbreak and the facility, the findings may not be generalizable to other settings.

\section{Conclusion}

This descriptive analysis is consistent with other investigations demonstrating that partial or complete COVID-19 vaccination provides protection for residents of LTC facilities, prevents severe infection and outcomes and highlights the importance of vaccination in these settings. However, breakthrough infections occur, and may be more common in elderly individuals due to their less robust immune response to vaccination $(4,18,19)$. This highlights the importance of continued vigilance regarding general IPAC measures, such as use of appropriate personal protective equipment, routine symptom screening and rapid isolation and testing of individuals who experience COVID-19 symptoms. In addition, since asymptomatic or mild infection appears more common in immunized individuals, asymptomatic testing is a critical tool for identifying and isolating cases before further transmission occurs. 


\section{Authors' statement}

FS - Writing original draft, review and editing, project administration

BG - Methodology and analysis, writing review and editing

MS - Methodology and analysis, writing review and editing

AW - Conceptualization, investigation and resources, writing original draft, review and editing

NP — Investigation and resources, writing review and editing

PR - Investigation and resources, writing review and editing

MA - Investigation and resources, writing review and editing

SP - Conceptualization, supervision, writing review and editing

\section{Competing interests}

None.

\section{Acknowledgements}

The outbreak management team acknowledges all the individuals at the Interior Health Authority who contributed to the outbreak investigation and management. In addition, the authors acknowledge Dr. Danuta Skowronski's invaluable contribution to this article.

\section{Funding}

This work was supported by the Interior Health Authority.

\section{References}

1. McMichael TM, Currie DW, Clark S, Pogosjans S, Kay M, Schwartz NG, Lewis J, Baer A, Kawakami V, Lukoff MD, Ferro J, Brostrom-Smith C, Rea TD, Sayre MR, Riedo FX, Russell D, Hiatt B, Montgomery P, Rao AK, Chow EJ, Tobolowsky F, Hughes MJ, Bardossy AC, Oakley LP, Jacobs JR, Stone ND, Reddy SC, Jernigan JA, Honein MA, Clark TA, Duchin JS; Public Health-Seattle and King County, EvergreenHealth, and CDC COVID-19 Investigation Team. Epidemiology of Covid-19 in a Long-Term Care Facility in King County, Washington. N Engl J Med 2020;382(21):2005-11. DOI PubMed

2. Vilches TN, Nourbakhsh S, Zhang K, Juden-Kelly L, Cipriano LE, Langley JM, Sah P, Galvani AP, Moghadas SM. Multifaceted strategies for the control of COVID-19 outbreaks in long-term care facilities in Ontario, Canada. Prev Med 2021;148:106564. DOI PubMed
3. Thompson MG, Burgess JL, Naleway $A L$, Tyner $\mathrm{HL}$, Yoon SK, Meece J, Olsho LE, Caban-Martinez AJ, Fowlkes A, Lutrick K, Kuntz JL, Dunnigan K, Odean MJ, Hegmann KT, Stefanski E, Edwards LJ, Schaefer-Solle N, Grant L, Ellingson K, Groom HC, Zunie T, Thiese MS, Ivacic L, Wesley MG, Lamberte JM, Sun X, Smith ME, Phillips AL, Groover KD, Yoo YM, Gerald J, Brown RT, Herring MK, Joseph G, Beitel S, Morrill TC, Mak J, Rivers P, Harris KM, Hunt DR, Arvay ML, Kutty P, Fry AM, Gaglani M. Interim Estimates of Vaccine Effectiveness of BNT162b2 and mRNA-1273 COVID-19 Vaccines in Preventing SARS-CoV-2 Infection Among Health Care Personnel, First Responders, and Other Essential and Frontline Workers - Eight U.S. Locations, December 2020-March 2021. MMWR Morb Mortal Wkly Rep 2021;70(13):495-500. DOI PubMed

4. Britton A, Jacobs Slifka KM, Edens C, Nanduri SA, Bart SM, Shang N, Harizaj A, Armstrong J, Xu K, Ehrlich HY, Soda E, Derado G, Verani JR, Schrag SJ, Jernigan JA, Leung VH, Parikh S. Effectiveness of the Pfizer-BioNTech COVID-19 Vaccine Among Residents of Two Skilled Nursing Facilities Experiencing COVID-19 Outbreaks - Connecticut, December 2020-February 2021. MMWR Morb Mortal Wkly Rep 2021;70(11):396-401. DOI PubMed

5. Teran RA, Walblay KA, Shane EL, Xydis S, Gretsch S, Gagner A, Samala U, Choi H, Zelinski C, Black SR. Postvaccination SARS-CoV-2 Infections Among Skilled Nursing Facility Residents and Staff Members - Chicago, Illinois, December 2020-March 2021. MMWR Morb Mortal Wkly Rep 2021;70(17):632-8. DOI PubMed

6. White EM, Yang X, Blackman C, Feifer RA, Gravenstein S, Mor V. Incident SARS-CoV-2 Infection among mRNA-Vaccinated and Unvaccinated Nursing Home Residents. N Engl J Med 2021;385(5):474-6. DOI PubMed

7. Madhi SA, Baillie $V$, Cutland $C L$, Voysey $M$, Koen $A L$, Fairlie L, Padayachee SD, Dheda K, Barnabas SL, Bhorat QE, Briner C, Kwatra G, Ahmed K, Aley P, Bhikha S, Bhiman JN, Bhorat AE, du Plessis J, Esmail A, Groenewald M, Horne E, Hwa SH, Jose A, Lambe T, Laubscher M, Malahleha M, Masenya M, Masilela M, McKenzie S, Molapo K, Moultrie A, Oelofse S, Patel F, Pillay S, Rhead S, Rodel H, Rossouw L, Taoushanis C, Tegally H, Thombrayil A, van Eck S, Wibmer CK, Durham NM, Kelly EJ, Villafana TL, Gilbert S, Pollard AJ, de Oliveira T, Moore PL, Sigal A, Izu A; NGS-SA Group; Wits-VIDA COVID Group. Efficacy of the ChAdOx1 nCoV-19 Covid-19 Vaccine against the B.1.351 Variant. $\mathrm{N}$ Engl J Med 2021;384(20):1885-98. DOI PubMed

8. Kustin T, Harel N, Finkel U, Perchik S, Harari S, Tahor M, Caspi I, Levy R, Leshchinsky M, Ken Dror S, Bergerzon G, Gadban H, Gadban F, Eliassian E, Shimron O, Saleh L, Ben-Zvi H, Keren Taraday E, Amichay D, Ben-Dor A, Sagas D, Strauss M, Shemer Avni Y, Huppert A, Kepten E, Balicer RD, Netzer D, Ben-Shachar S, Stern A. Evidence for increased breakthrough rates of SARS-CoV-2 variants of concern in BNT162b2-mRNA-vaccinated individuals. Nat Med 2021;27(8):1379-84. DOI PubMed 
9. Hacisuleyman E, Hale C, Saito Y, Blachere NE, Bergh M, Conlon EG, Schaefer-Babajew DJ, DaSilva J, Muecksch F, Gaebler C, Lifton R, Nussenzweig MC, Hatziioannou T, Bieniasz PD, Darnell RB. Vaccine Breakthrough Infections with SARS-CoV-2 Variants. N Engl J Med 2021;384(23):2212-8. DOI PubMed

10. BC Centre for Disease Control. British Columbia (BC) COVID-19 Situation Report, Week 9: Feb 28-March 6, 2021. BCCDC; 2021 (accessed 2021-04-30). http://www.bccdc.ca/ Health-Info-Site/Documents/COVID_sitrep/Week_9_2021_ BC_COVID-19_Situation_Report.pdf

11. BC Centre for Disease Control. COVID-19 Infection prevention and Control: Guidance for Long-term care and seniors' assisted living settings. BCCDC; 2021 (accessed 2021-04-30). http://www.bccdc.ca/Health-Info-Site/ Documents/COVID19_LongTermCareAssistedLiving.pdf

12. BC Centre for Disease Control. British Columbia (BC) COVID-19: Outbreak management protocol for acute care, long-term care and seniors' assisted living setting. BCCDC; 2021 (accessed 2021-04-30). http://www.bccdc.ca/ Health-Professionals-Site/Documents/COVID-19_Provincial_ Outbreak_Management_Protocol_LTC.pdf

13. BC Centre for Disease Control. COVID-19 Case Report Form. BCCDC; 2021. (accessed 2021-04-31). http://www. bccdc.ca/Documents/COVID-19_Case_Report_Form.pdf

14. BC Centre for Disease Control. Interim Guidance: Public health management of cases and contacts associated with novel coronavirus (COVID-19) in the community. BCCDC; 2021 (accessed 2021-08-20). http://www.bccdc. $\mathrm{ca} /$ resource-gallery/Documents/Guidelines\%20and\%20 Forms/Guidelines\%20and\%20Manuals/Epid/CD\%20Manual/ Chapter\%201\%20-\%20CDC/2019-nCoV-Interim_Guidelines. pdf

15. BC Centre for Disease Control. Weekly COVID-19 long term care assisted living \& independent living outbreak report. BCCDC; 2021 (accessed 2021-08-20). http://www.bccdc. ca/Health-Info-Site/Documents/COVID_sitrep/Weekly_ COVID-19_Outbreak_Report_05062021.pdf

16. Müller L, Andrée M, Moskorz W, Drexler I, Walotka L, Grothmann R, Ptok J, Hillebrandt J, Ritchie A, Rabl D, Ostermann PN, Robitzsch R, Hauka S, Walker A, Menne C, Grutza R, Timm J, Adams O, Schaal H. Age-dependent immune response to the Biontech/Pfizer BNT162b2 COVID-19 vaccination. Clin Infect Dis. 2021 Apr 27:ciab381. DOI PubMed
17. Collier DA, Ferreira IATM, Kotagiri P, Datir RP, Lim EY, Touizer E, Meng B, Abdullahi A; CITIID-NIHR BioResource COVID-19 Collaboration, Elmer A, Kingston N, Graves B, Le Gresley E, Caputo D, Bergamaschi L, Smith KGC, Bradley JR, Ceron-Gutierrez L, Cortes-Acevedo P, Barcenas-Morales G, Linterman MA, McCoy LE, Davis C, Thomson E, Lyons PA, McKinney E, Doffinger R, Wills M, Gupta RK. Age-Related immune responses to SARS-CoV-2 vaccine BNT162b2. Nature. 2021;596(7872):417-22. DOI PubMed

18. Tenforde MW, Olson SM, Self WH, Talbot HK, Lindsell CJ, Steingrub JS, Shapiro NI, Ginde AA, Douin DJ, Prekker ME, Brown SM, Peltan ID, Gong MN, Mohamed A, Khan A, Exline MC, Files DC, Gibbs KW, Stubblefield WB, Casey JD, Rice TW, Grijalva CG, Hager DN, Shehu A, Qadir N, Chang SY, Wilson JG, Gaglani M, Murthy K, Calhoun N, Monto AS, Martin ET, Malani A, Zimmerman RK, Silveira FP, Middleton DB, Zhu Y, Wyatt D, Stephenson M, Baughman A, Womack KN, Hart KW, Kobayashi M, Verani JR, Patel MM; IVY Network; HAIVEN Investigators. Effectiveness of Pfizer-BioNTech and Moderna Vaccines Against COVID-19 Among Hospitalized Adults Aged $\geq 65$ Years - United States, January-March 2021. MMWR Morb Mortal Wkly Rep 2021;70(18):674-9. DOI PubMed

19. Quach C, Deeks S. COVID-19 vaccination: why extend the interval between doses? JAMMI 2021;6(2):73-8. DOI

20. Polack FP, Thomas SJ, Kitchin N, Absalon J, Gurtman A, Lockhart S, Perez JL, Pérez Marc G, Moreira ED, Zerbini C, Bailey R, Swanson KA, Roychoudhury S, Koury K, Li P, Kalina WV, Cooper D, Frenck RW Jr, Hammitt LL, Türeci Ö, Nell H, Schaefer A, Ünal S, Tresnan DB, Mather S, Dormitzer PR, Şahin U, Jansen KU, Gruber WC; C4591001 Clinical Trial Group. Safety and Efficacy of the BNT162b2 mRNA Covid-19 Vaccine. N Engl J Med 2020;383(27):2603-15. DOI PubMed 